\title{
Hybrid ferrofluid along with MWCNT for augmentation of thermal behavior of fluid during natural convection in a cavity
}

\author{
Yu-Ming Chu ${ }^{1,2}$, S. Bilal ${ }^{3}$, and Mohammed Reza Hajizadeh ${ }^{3}$ \\ ${ }^{1}$ Huzhou University, China \\ ${ }^{2}$ Huzhou University \\ ${ }^{3}$ Affiliation not available
}

November 2, 2020

\begin{abstract}
Current pagination concerns with exploration regarding thermal characteristics induced by Hybridization of with MWCNT in a permeable tank filled with viscous fluid with magnetization. Roseland approximation is obliged to configure radiative heat flux aspects. Modeling and structuring of considered problem is established in partial differential setup. CVFEM is implemented to seek out solution of constructed differential layout. Data establishing properties of with MWCNT's is disclosed in tabular format. Impression of sundry variables in view of isotherm and stream pattern is divulged. Local convective thermal rate against involved variables in 3D snapshots is captured. Test about grid independence and comparison with conducted work to get assurance of present finding is explicated. It is deduced that heat transfer along walls enhances verses Rayleigh and Darcy parameters whereas delineates against mounting effect of magnetic field strength.
\end{abstract}

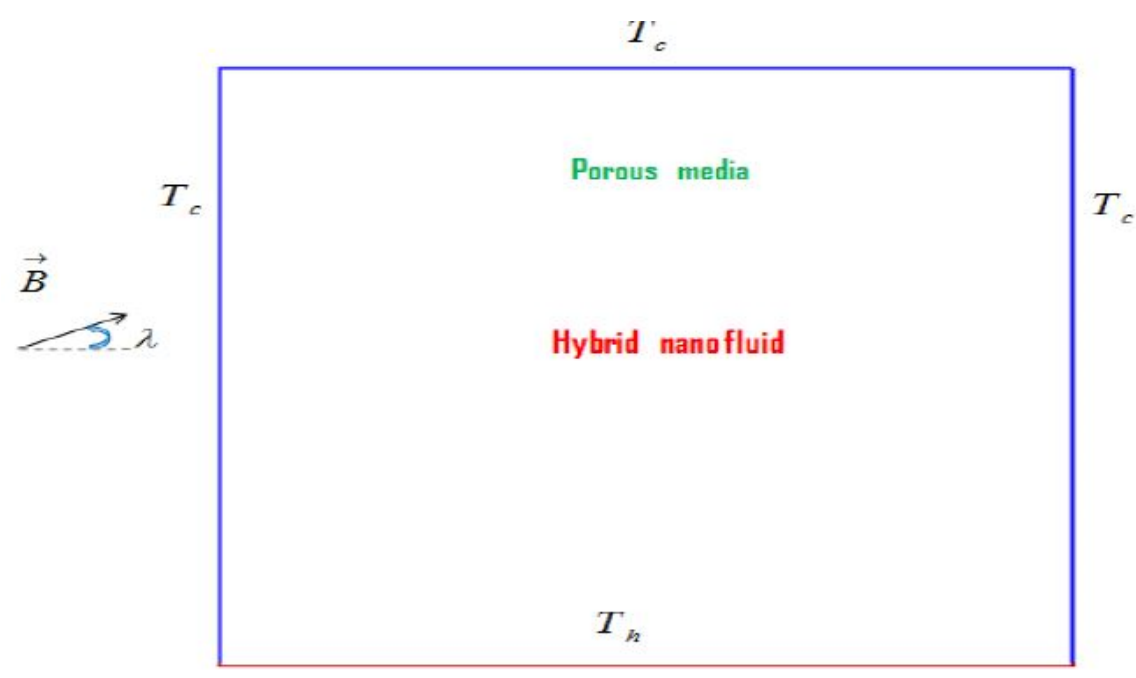



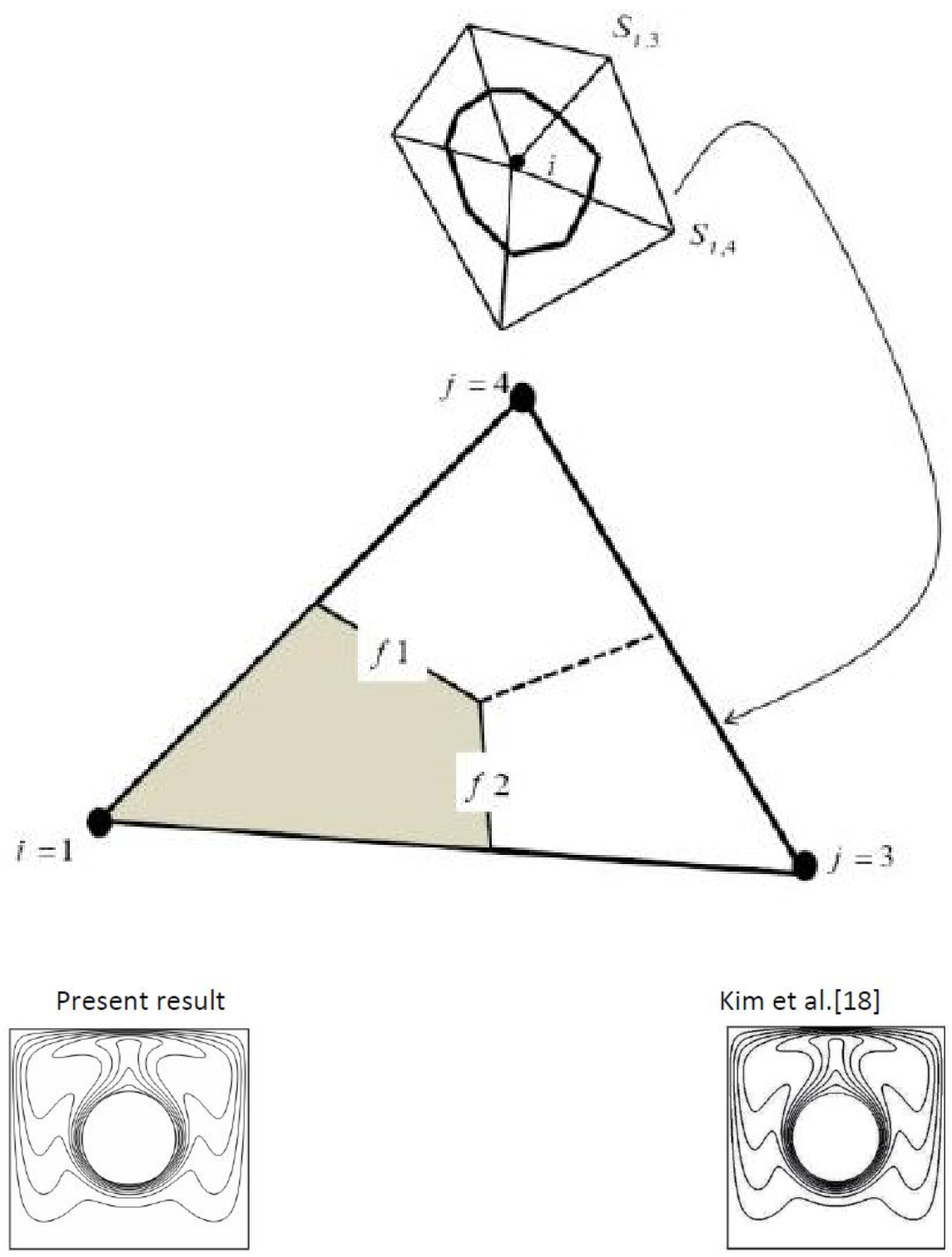


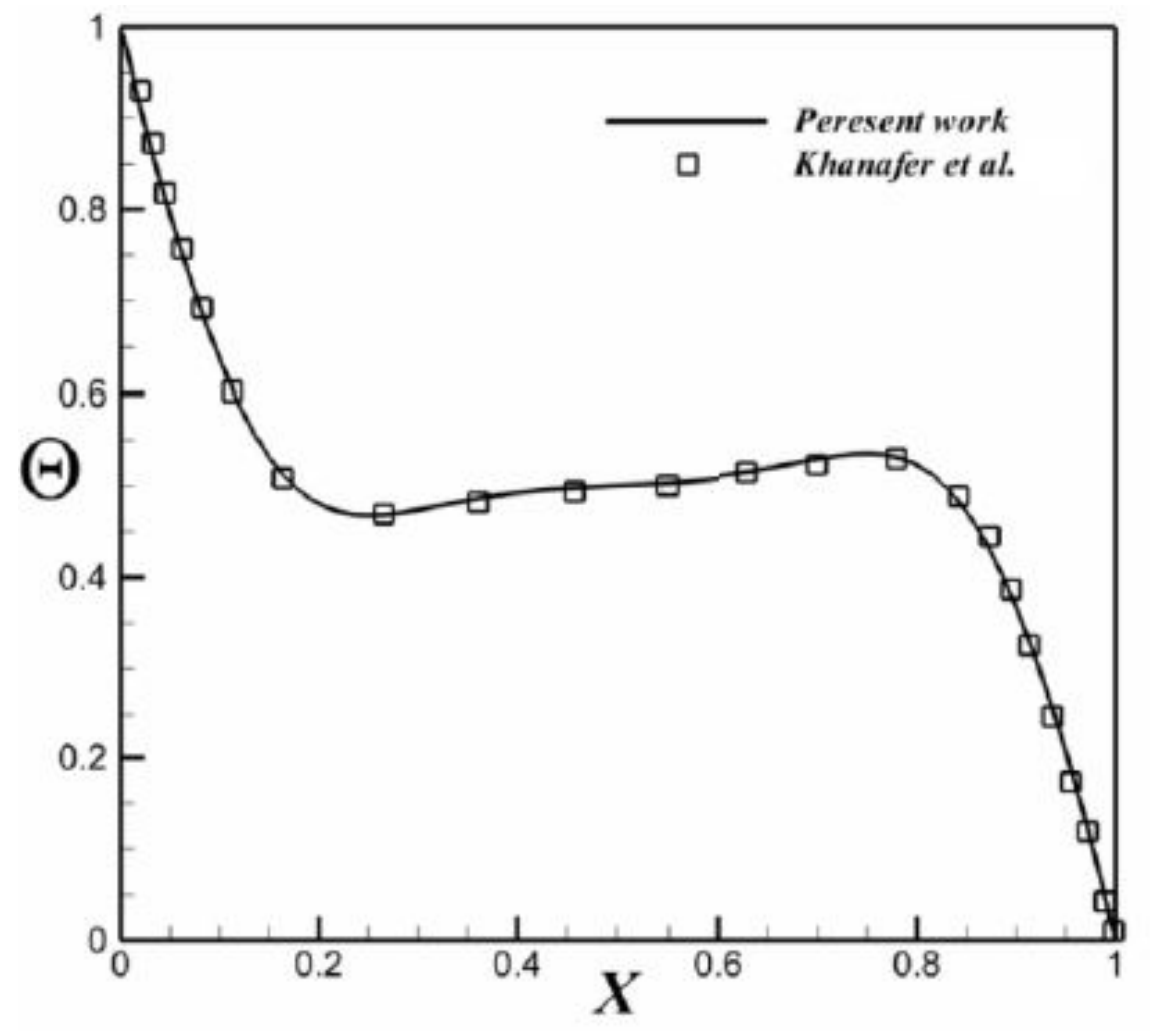




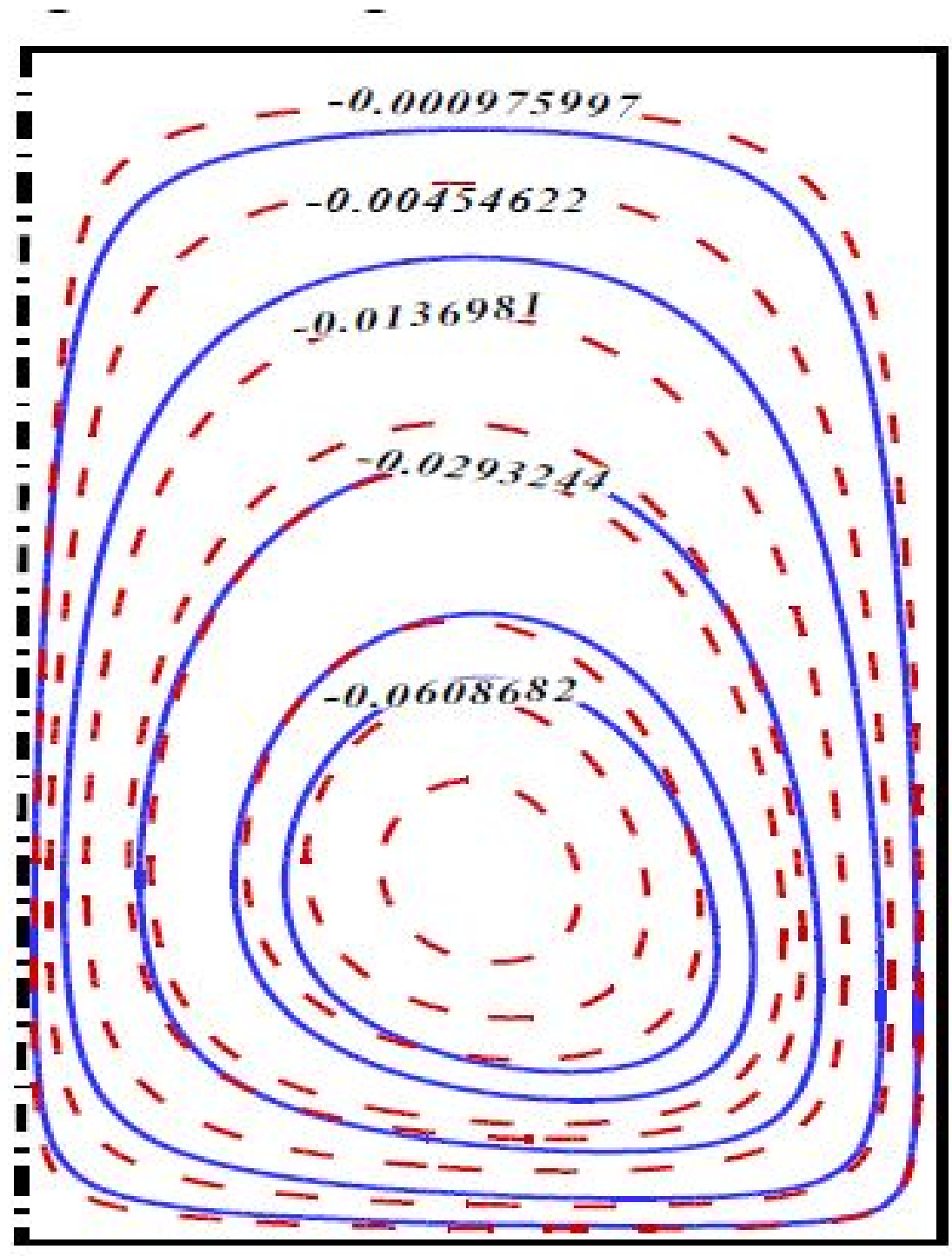




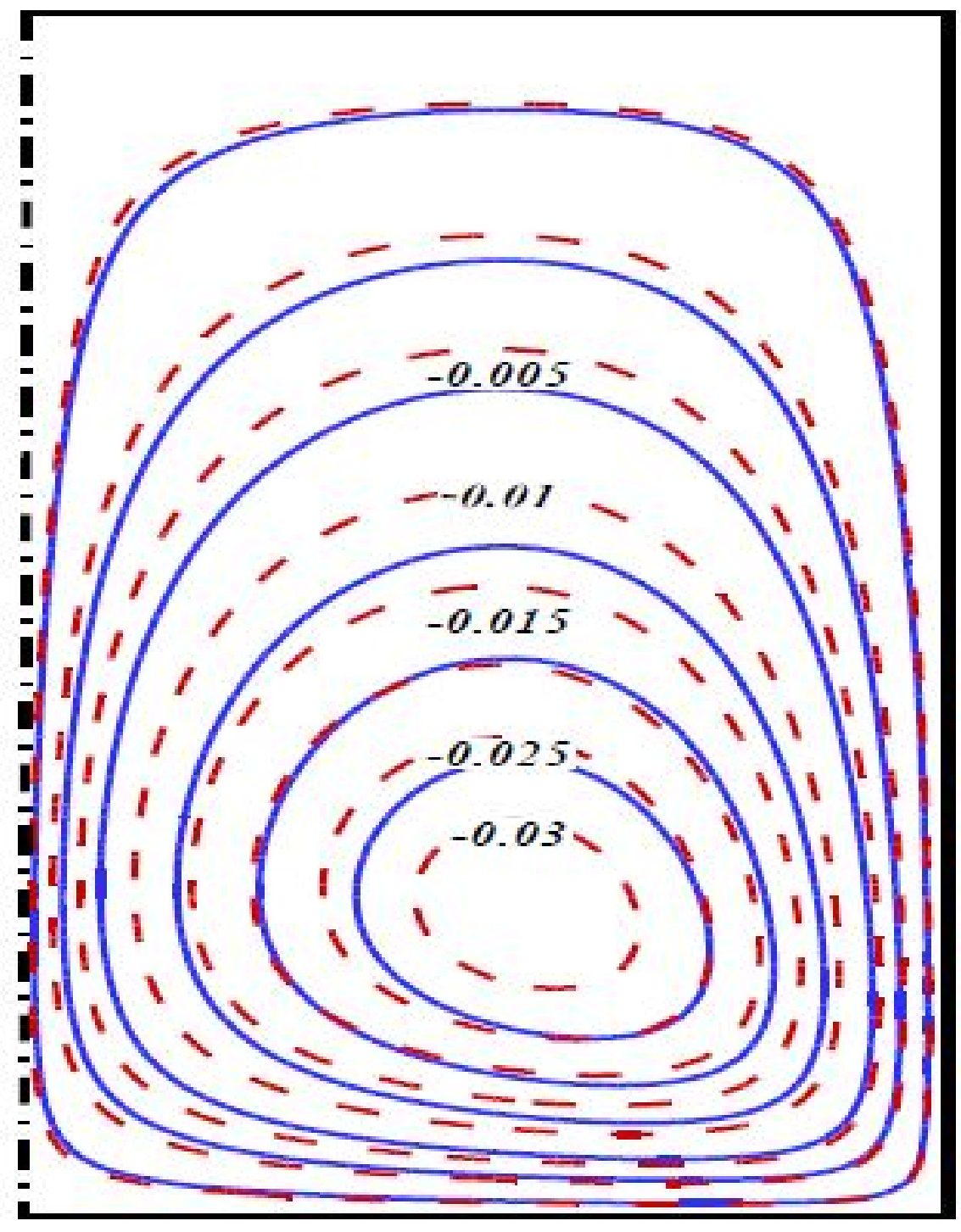




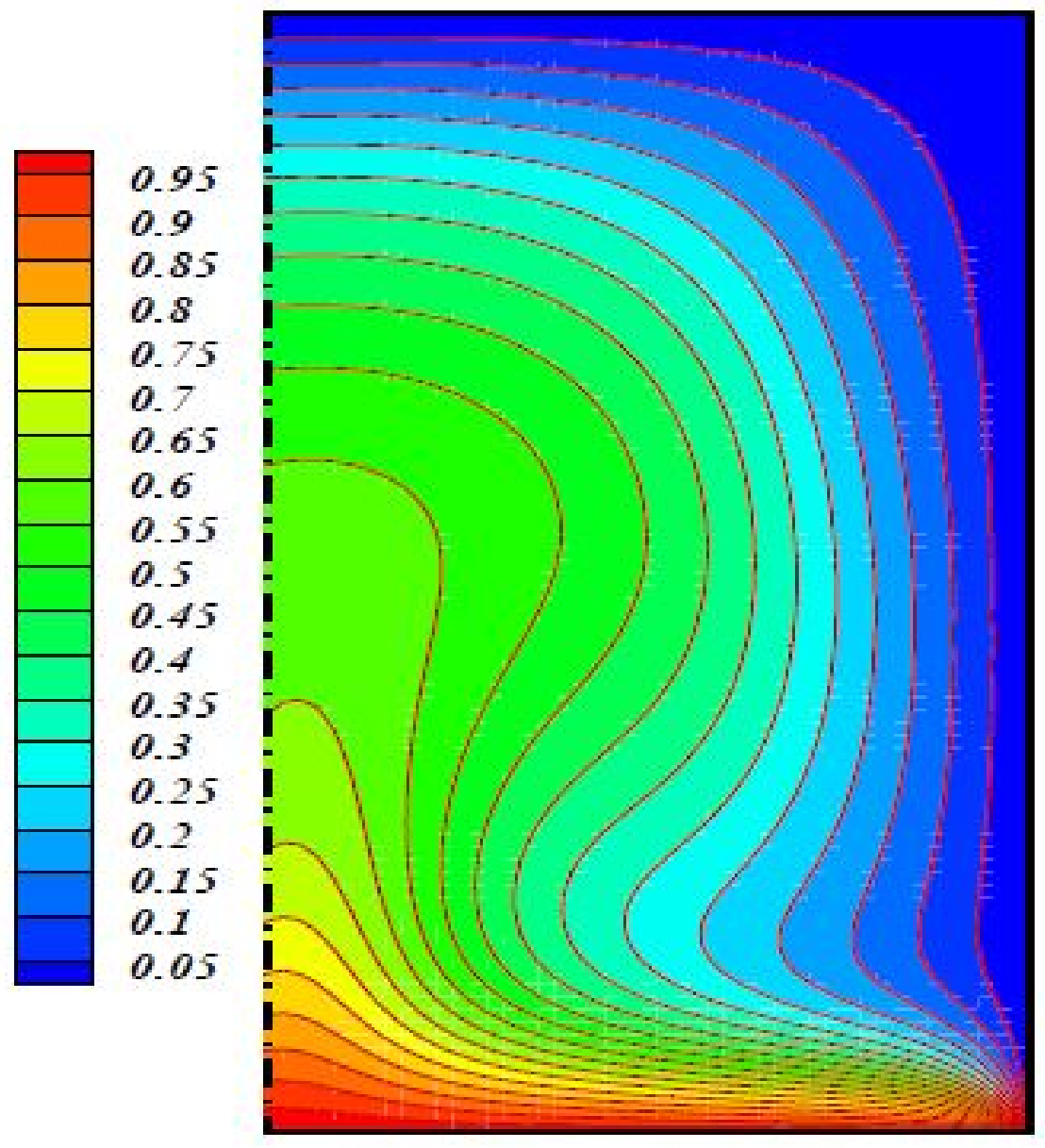




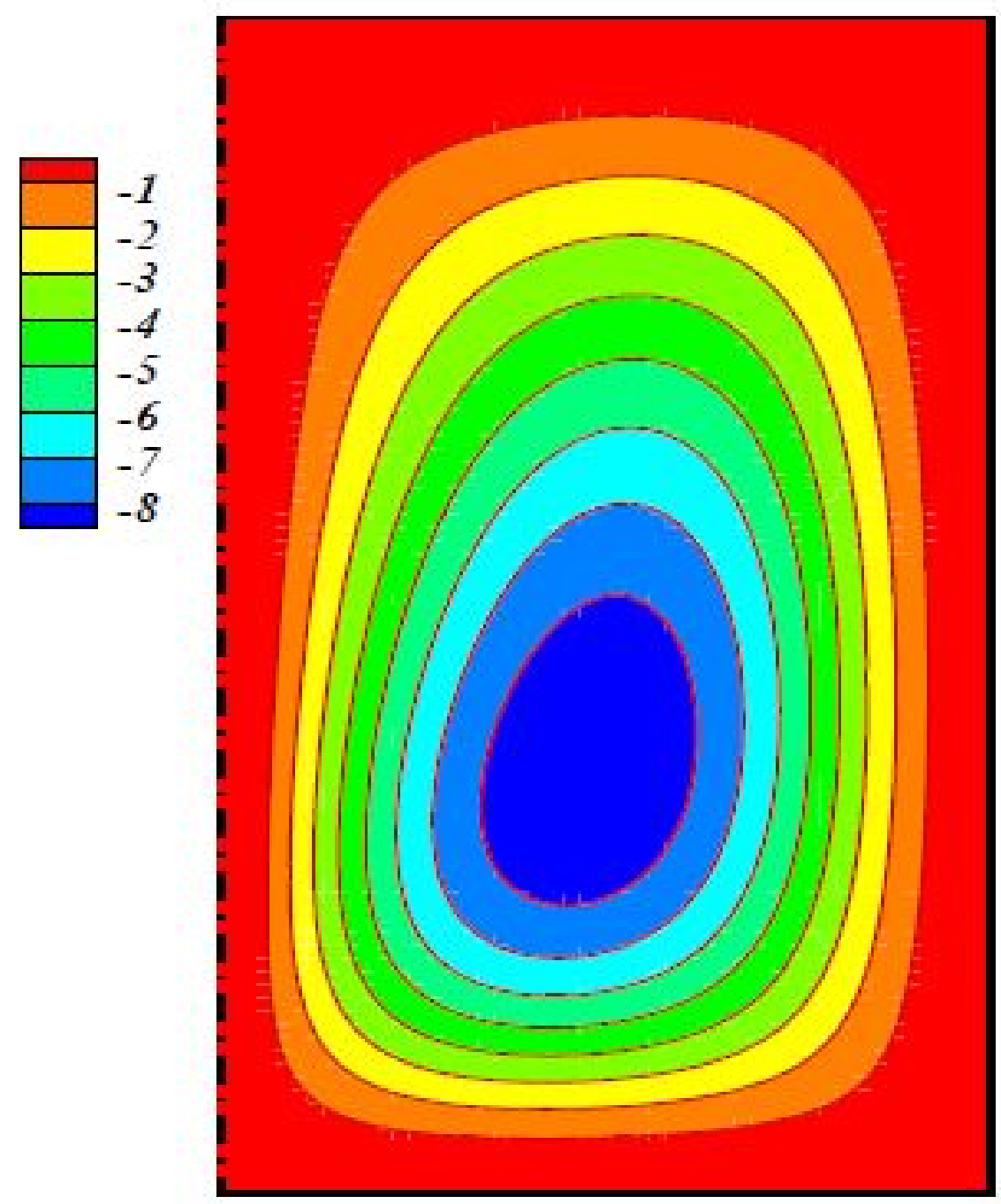




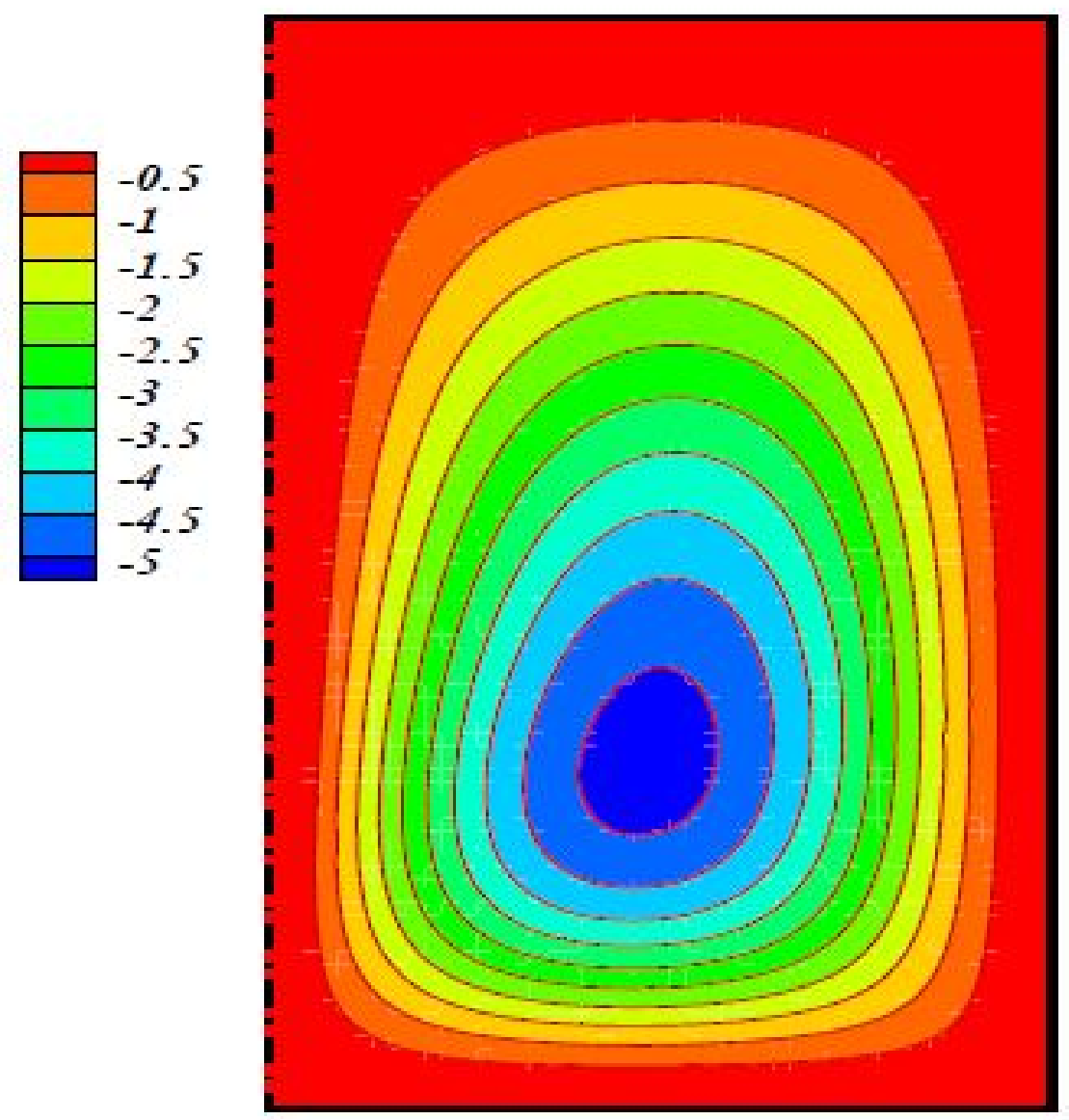




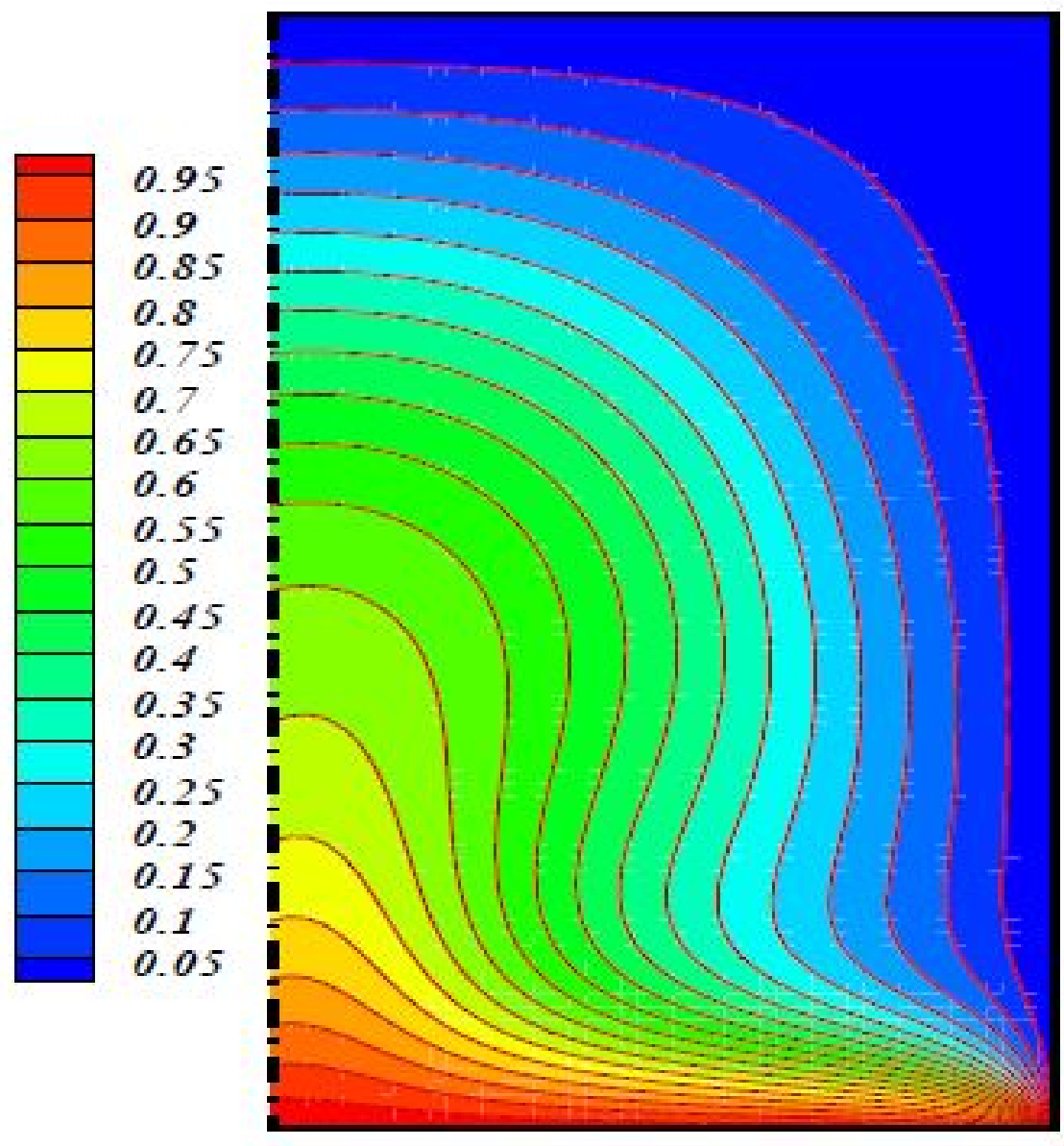




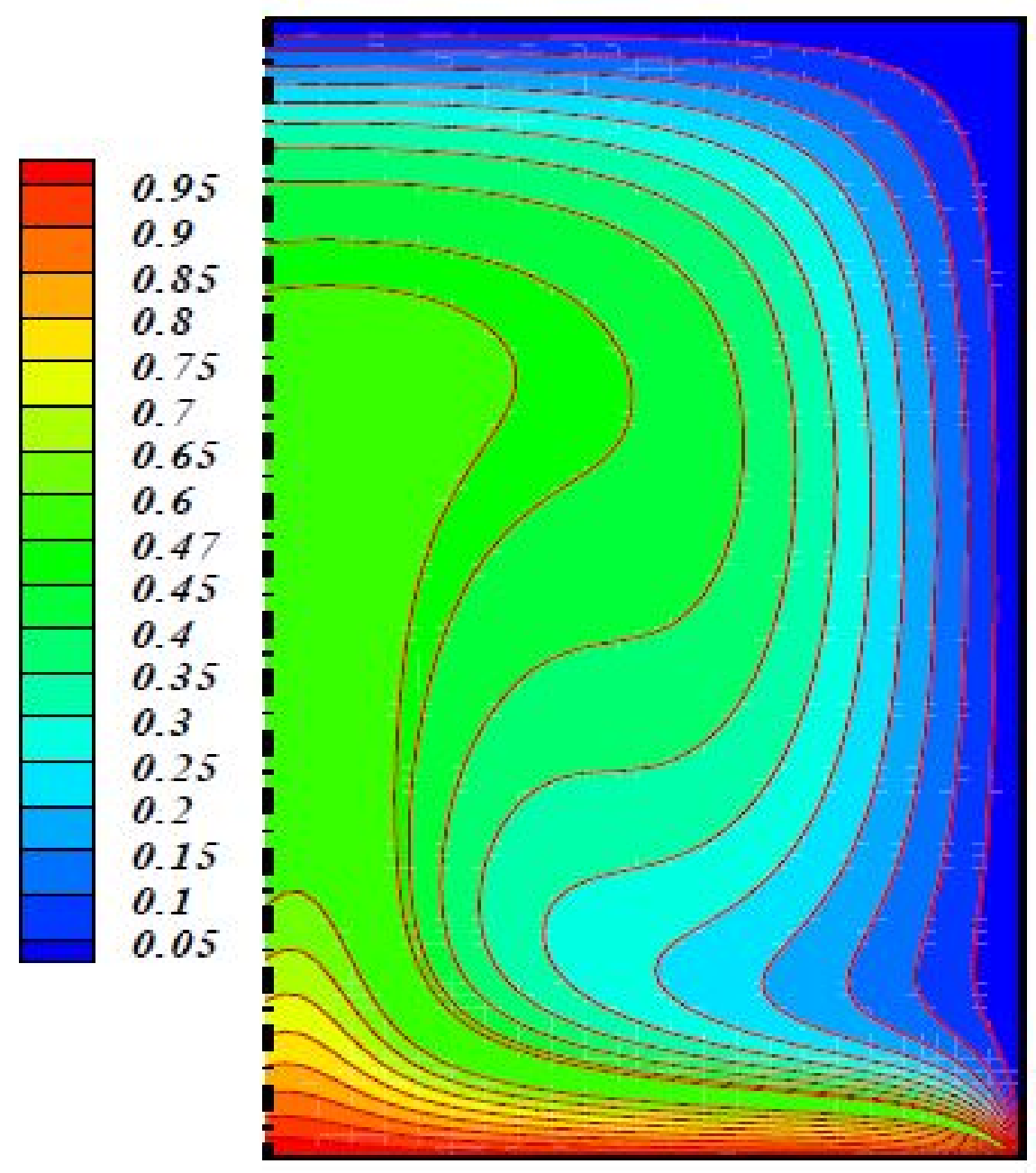




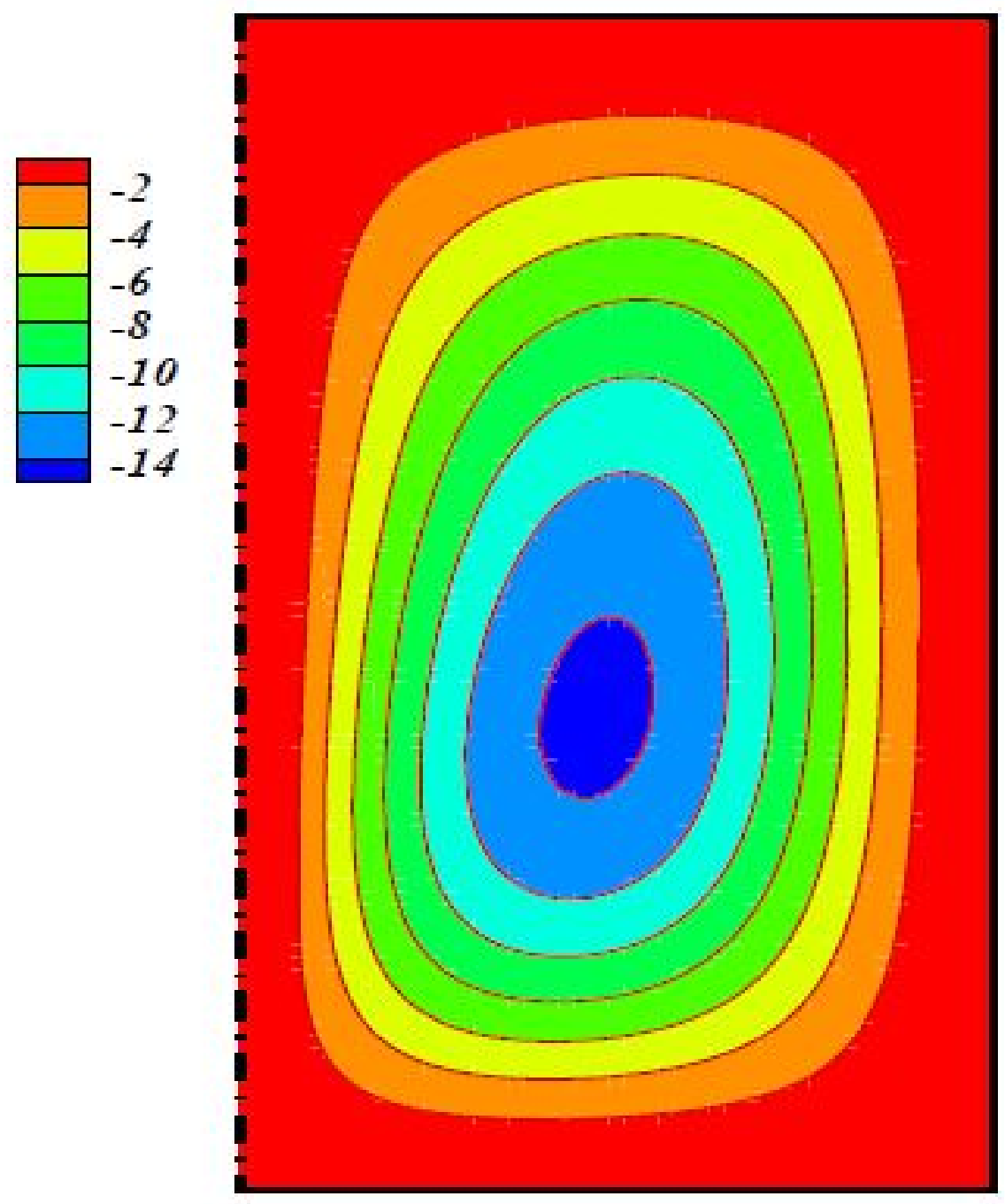




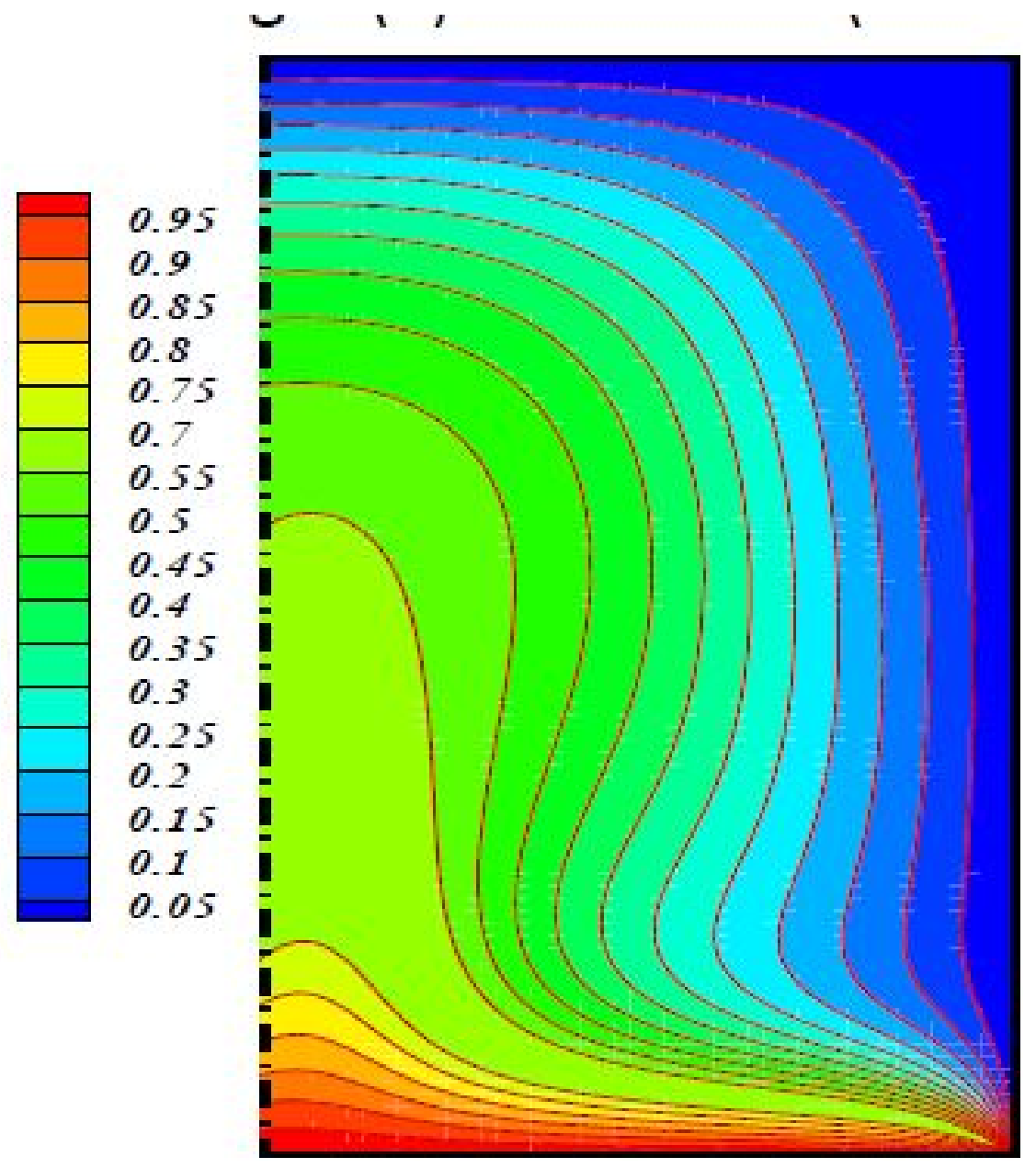



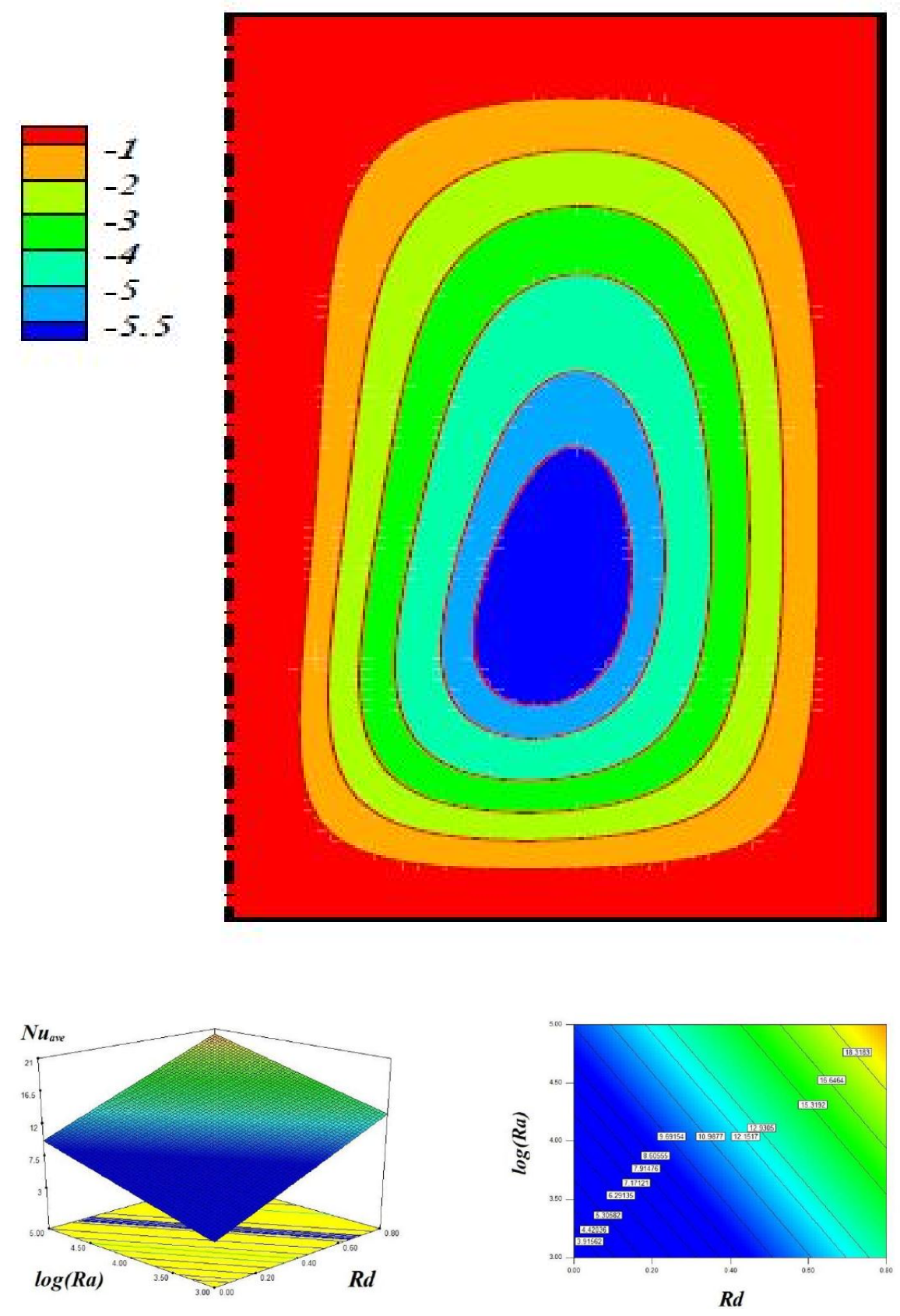

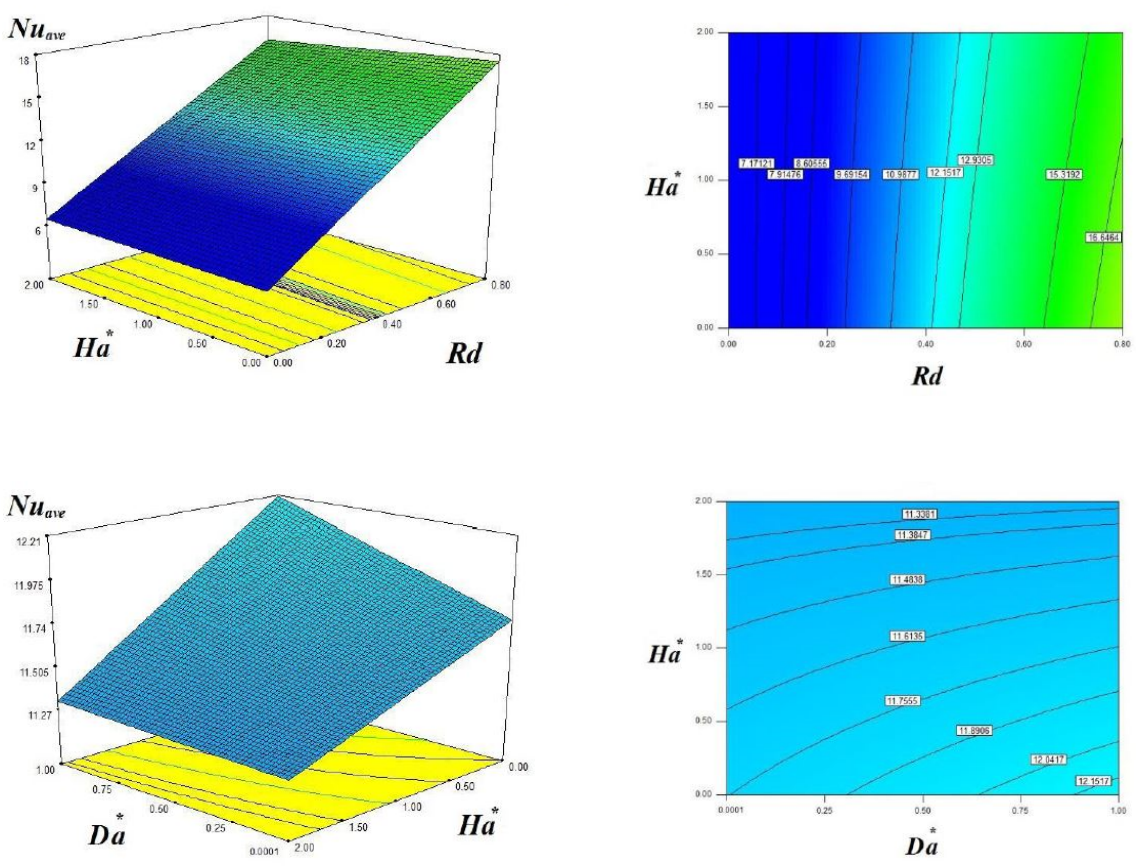